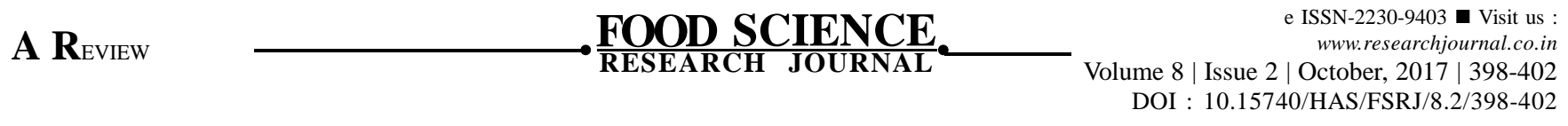

\title{
A review on Snapshot of Indian Dairy Industry
}

\begin{abstract}
NIHA KHAN
The basic purpose of this literature review based article is to understand the present situation of dairy industry in India and different issues of the stakeholders of the business. This is a survey of research articles identified with dairy industry. The real issues uncovered were identified with absence of feed and focuses, shortage of veterinary and analytic administrations, absence of data and innovative mindfulness. These were regular issues confronted by dairy agriculturists in the greater part of the locales of India. Acquirement cost was observed to be the significant segment of aggregate expenses took after by preparing cost. These reviews assessed the monetary feasibility of concerned dairy units.
\end{abstract}

Key Words : Milk, Operation flood, Milk co-operatives, Indian dairy, Dairying

How to cite this article : Khan, Niha (2017). A review on Snapshot of Indian Dairy Industry. Food Sci. Res. J., 8(2): 398-402, DOI : 10.15740/HAS/FSRJ/8.2/398-402.

Email : nihakhan8@gmail.com 